\title{
Our Hero of the Anniversary
}

\section{Arkadiy Alekseyevich Chikrii}

On July 20, 2020, a prominent Ukrainian scientist, specialist in the field of applied mathematics and cybernetics, Academician of the National Academy of Sciences of Ukraine, Editor-in-chief of our journal Arkadiy Alekseyevich Chikrii turned 75.

A.A. Chikrii was born in the Khmelnitskiy region of Ukraine, graduated from the Faculty of Mechanics and Mathematics of the Ivan Franko Lvov State University, and since 1968 has been working at the V.M. Glushkov Institute of Cybernetics of National Academy of Sciences of Ukraine, starting from an engineer to the head of the department of optimization of controlled processes.

In 1979 he became a doctor of sciences (physics and mathematics).

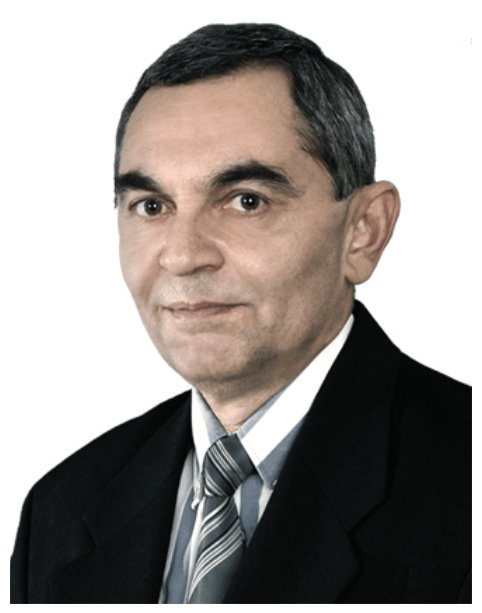

The main directions of the scientific activities of A.A. Chikrii are applied nonlinear analysis, extreme problems, mathematical control theory, dynamic game theory, the theory of searching for moving objects, the creation of computer technologies for the analysis of conflict situations. He is a pupil and follower of L.S. Pontryagin, N.N. Krasovsky, and B.N. Pshenichnyi.

A.A. Chikrii laid the foundations for the nonlinear theory of collision avoidance by developing several methods; developed the theory of positional group pursuit, proposed the Markov models for searching for moving objects. One of the greatest scientific achievements of A.A. Chikrii is a method of resolving functions, which is a consequence of the special minimaximin function introduced by him in the theory of evading. This method, in particular, provides a complete theoretical substantiation of the classical rules for parallel pursuit and rendezvous along a ray, which are well known to designers of rocket and space technology.

The last works of A.A. Chikrii deal with the study of conflict-controlled processes based on multivalued mappings for systems with fractional derivatives, distributed parameters.

In parallel with theoretical research A.A. Chikrii, together with researchers of the department developed several problem-oriented computer systems, modeling complexes and simulators associated with decisionmaking and control of moving objects under conditions of conflict confrontation and uncertainty.

A.A. Chikrii is the author of over 550 scientific works, including 6 monographs and 28 surveys in the form of separate chapters in books of international groups of authors. He trained about 40 candidates and doctors of sciences.

ISSN 1064-2315

(C) 2020 by Begell House Inc. 
$\mathrm{He}$ is a member of the editorial boards of several foreign mathematical journals and has a high rank in international scientometric databases.

A.A. Chikrii is the laureate of the State Prize of Ukraine in the field of science and technology, the State Prize of Ukraine in the field of education, the V.M. Glushkov Prize of National Academy of Sciences of Ukraine, won several international research grants.

Arkadiy Alekseyevich has his own research style. He has excellent intuition, sets new problems and takes on the most difficult ones showing great ingenuity in the creation of constructive solutions with following elegant analytical justifications.

The editorial board, editorial staff, colleagues and pupils sincerely wish the Editor-in-chief strong health, inexhaustible energy, implementation of all ideas and new creative successes. 